\title{
LEAD (Pb) EXPOSURE THROUGH DRINKING WATER: LESSONS TO BE LEARNED FROM RECENT U.S. EXPERIENCE
}

\author{
S. TRIANTAFYLLIDOU ${ }^{1, *}$ \\ Y. LAMBRINIDOU ${ }^{2}$ \\ M. EDWARDS ${ }^{1}$
}

\author{
${ }^{1} 418$ Durham Hall, Civil and Environmental Engineering Dept, \\ Virginia Tech, Blacksburg VA 24061, USA \\ ${ }^{2}$ Parents for Nontoxic Alternatives, \\ Washington DC 20015, USA
}

Received: 14/10/08

*to whom all correspondence should be addressed:

Accepted: 20/02/09 e-mail: striant@vt.edu

\begin{abstract}
Lead $(\mathrm{Pb})$ particles that detach from the plumbing and contaminate drinking water can pose a significant health threat, which is often underestimated. Laboratory simulation of this problem revealed that standard quantification protocols in the US may miss $80 \%$ of the lead present in the water. At the same time, a significant fraction of this undetected particulate lead may be bioavailable when ingested. A critical review of the Washington DC lead-in-water crisis suggested that lead in water might constitute a greater public health risk than generally acknowledged, in at least some circumstances. It also revealed deficiencies in the public health response as well as in alerting the public to elevated levels of lead, and the subject continues to be mired in controversy. Our independent testing at six Washington DC public schools in 2008 showed that problems with elevated lead still persist at $2-41 \%$ of taps sampled at each school, even after remedial measures were implemented.
\end{abstract}

KEYWORDS: lead, particles, water, sampling protocol, potential bioavailability, Washington DC lead-in-water crisis.

\section{INTRODUCTION}

Lead $(\mathrm{Pb})$ exposure through drinking water accounts on average for $20 \%$ of total lead exposure in the United States (US) (US EPA, 2005). Recent instances of blood lead poisoning which were linked to the water (Triantafyllidou et al., 2007; Triantafyllidou, 2006), combined with the known harmful effects of low-level lead exposure (Bellinger, 2003), have instigated reassessment of this problem nationally.

The US Environmental Protection Agency (EPA), which regulates public water supplies under the Lead and Copper Rule (LCR), has set an "action level" for lead at home taps of $15 \mathrm{ug} \mathrm{L}^{-1}$ (US EPA, 1991). To check compliance with this action level, drinking water sampling for lead in the US typically involves the following steps (US EPA, 1994a):

- Water sample collection at the tap (usually by homeowner)

- Shipment to the lab

- Acidification of sample to $\mathrm{pH}<2.0$, by addition of $0.15 \% \mathrm{v} / \mathrm{v}$ nitric acid $\left(\mathrm{HNO}_{3}\right)$

- Minimum holding time of 16 hours

- Turbidity measurement, and additional acid digestion only if the turbidity is greater than 1 ntu (nephelometric turbidity unit)

- Lead quantification using ICP-MS (Inductively Coupled Plasma Mass Spectrometry) or other approved methods.

The success of the above protocol depends on the chemical form of the lead. That is, the existing protocol assumes that lead is soluble or can be dissolved within 16 hours at $\mathrm{pH}<2.0$. This assumption may prove problematic if lead particles are present in a water sample (Triantafyllidou et al., 2007). 
Recent cases of childhood lead poisoning, in Washington DC, Greenville North Carolina and Durham North Carolina were tied to lead particles in tap water. Particulate lead was identified by the authors in faucet aerators and in the water, at lead-poisoned children's homes. The particulate lead mostly originated from solder or lead corrosion by-products (e.g., lead rust), which detached from the plumbing and contaminated the water supply. The authors argue that similar instances are occurring elsewhere, but are not being detected.

When high levels of lead are identified in the water, the health threat can be easily and inexpensively eliminated. Mitigation of such a problem requires notification of the hazard and public education. During the Washington DC lead-in-water crisis, the public was belatedly informed about elevated lead in the city's water. The health risk associated with prolonged exposure to this lead hazard remains a topic of dispute up to date. Review of this case is of particular importance, as the "lessons learned" are surprisingly dependent on who is telling the story. This work can serve to guide lawmakers, civil servants, health professionals, the media and lead poisoning prevention advocates in similar future cases, in the US and other countries.

\section{MATERIALS AND METHODS}

The first part of this paper consists of a laboratory experiment, in which leaded particles are present in drinking water samples. The second part is a critical review of the Washington DC lead-in-water crisis.

\subsection{Evaluation of the standard US quantification protocol for lead in drinking water}

The objective of the experimental part was to assess the effectiveness of the standard US preservation protocol (method 200.8 of the US Environmental Protection Agency-EPA) in recovering the lead from representative particles that may be present in drinking water. For comparison reasons, dissolution of the leaded particles was examined in simulated gastric fluid (SGF) as well (Table 1). The SGF consisted of $0.2 \% \mathrm{NaCl}, 0.32 \%$ pepsin and $0.7 \% \mathrm{HCl}$ (US Pharmacopoeial Convention, 2005), had a pH of about 1.2, was heated at body temperature and was mildly shaken in order to simulate conditions inside the human stomach (Intawongse and Dean, 2006). For the purposes of this study it was assumed that lead solubility and lead bioavailability are strongly related. Thus, the SGF tests aimed to simulate potential bioavailability of the leaded particles inside the human stomach, after they are ingested through drinking water consumption.

Table 1. Comparison of the standard US EPA preservation protocol versus SGF

\begin{tabular}{|c|c|c|c|c|c|c|}
\hline & Constituents & $\begin{array}{c}\text { Typical } \\
\text { pH (-) }\end{array}$ & $\begin{array}{l}\text { Temperature } \\
\left.\text { ( }{ }^{\circ} \mathrm{C}\right)\end{array}$ & $\begin{array}{l}\text { Mixing } \\
\text { Pattern }\end{array}$ & $\begin{array}{l}\text { Holding } \\
\text { Time (h) }\end{array}$ & Reference \\
\hline $\begin{array}{c}\text { US EPA } \\
\text { Preservation } \\
\text { Protocol }\end{array}$ & $0.15 \% \mathrm{HNO}_{3}$ & 1.9 & $\begin{array}{c}20-22 \\
\text { (Room } \\
\text { Temperature) }\end{array}$ & Stagnant & $\begin{array}{c}16 \\
\text { (Minimum) }\end{array}$ & $\begin{array}{c}\text { US EPA, } \\
1994 a\end{array}$ \\
\hline $\begin{array}{l}\text { Simulated } \\
\text { Gastric Fluid } \\
\text { (SGF) }\end{array}$ & $\begin{array}{c}0.7 \% \mathrm{HCl} \\
\mathrm{NaCl} \\
\text { Pepsin }\end{array}$ & 1.2 & $\begin{array}{c}37 \\
\text { (Body } \\
\text { Temperature) }\end{array}$ & $\begin{array}{c}\text { Mild } \\
\text { Agitation }\end{array}$ & $\begin{array}{c}3 \\
\text { (typical for } \\
\text { solid } \\
\text { food)* }\end{array}$ & $\begin{array}{c}\text { US } \\
\text { Pharmacooeial } \\
\text { Convention, } \\
2005 \\
\text { Intawongse } \\
\text { and Dean, } \\
2006\end{array}$ \\
\hline
\end{tabular}

${ }^{*}$ could be but much longer in case of particle entrapment in the folds of the intestine.

During a thorough on-site investigation by the authors in Greenville, North Carolina, particles were found to be trapped in the aerator screen of a lead-poisoned child's kitchen faucet (Figure 1, left). Surface analysis of these particles (Figure 1, right) was conducted with a field emission scanning electron microscope (FE-SEM) equipped with electron dispersive spectroscopy (EDS). This instrument is useful for identifying elements of interest with respect to pipe/plumbing materials' corrosion. 

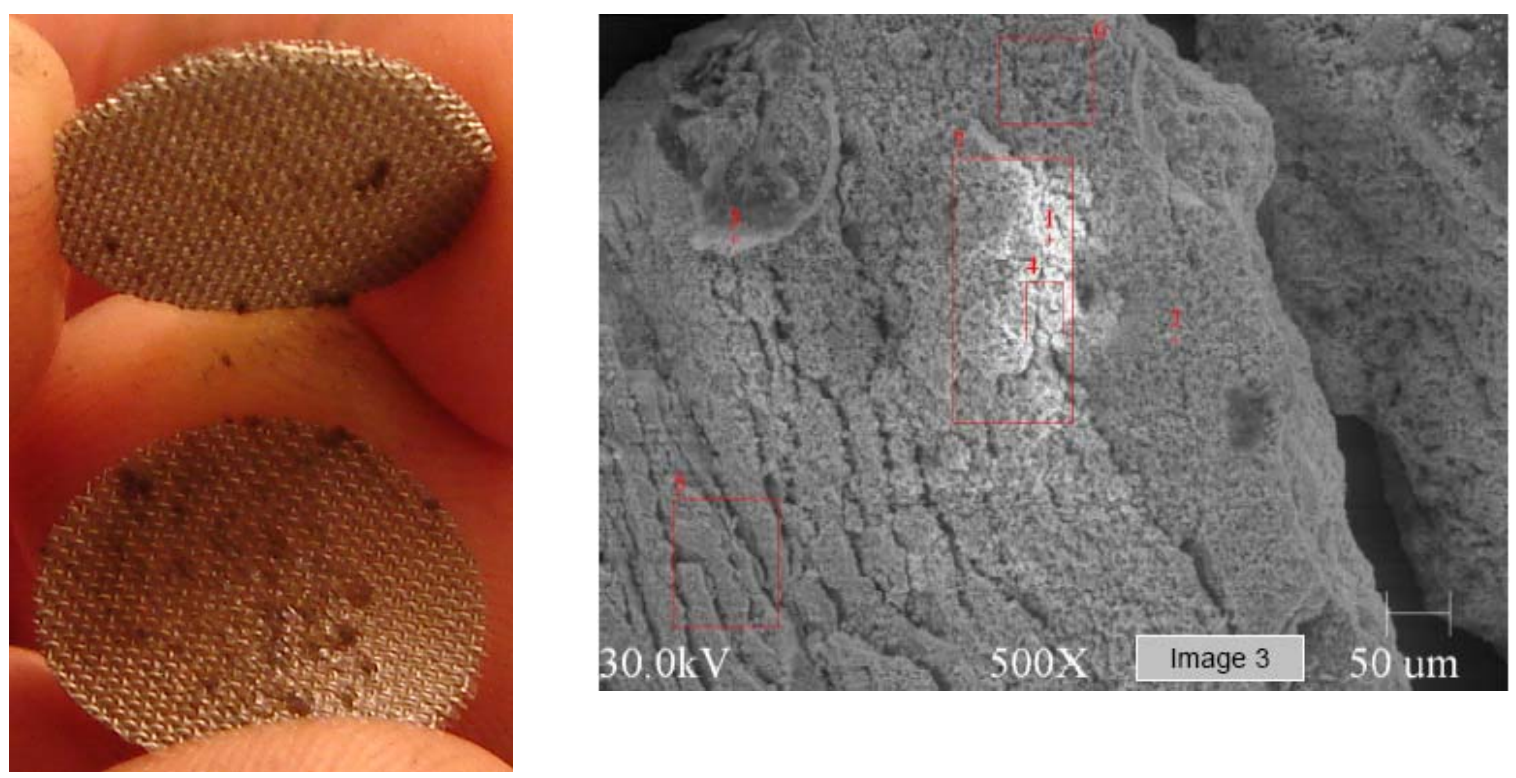

Figure 1. Particles trapped on faucet aerator screen in building of lead-poisoned child (left). Surface site analysis using SEM (right), revealed that the particles originated from lead/tin solder

The analysis revealed that the particles originated from lead/tin solder, due to the abundance of tin $(\mathrm{Sn})$ and presence of lead $(\mathrm{Pb})$ in their surface (Table 2).

Table 2. Elemental composition for the particle corresponding to Figure 1 right, based on SEM. The surface analysis results are presented as percent abundance by mass

\begin{tabular}{ccccccc}
\hline Element & Average & St. Dev. & Count & Max & Min & Median \\
\hline $\mathbf{O}$ & 18.4 & 4.1 & 7 & 21.7 & 9.5 & 19.3 \\
\hline $\mathbf{C u}$ & 0.8 & 0.2 & 7 & 1.0 & 0.6 & 0.8 \\
\hline $\mathrm{Sn}$ & 59.9 & 4.5 & 7 & 68.5 & 56.7 & 57.3 \\
\hline $\mathbf{P b}$ & 20.8 & 2.6 & 7 & 24.1 & 16.8 & 21.1 \\
\hline
\end{tabular}

Lead dissolution was investigated in water samples to which the leaded particles were added. Six similar particles weighing $5.0 \pm 0.3 \mathrm{mg}$ were gathered from the aerator screen and utilized in the experiment. Each particle was exposed to 1 liter of synthesized water $\left(82 \mathrm{mg} \mathrm{l}^{-1}\right.$ $\left.\mathrm{CaCl}_{2} \cdot 2 \mathrm{H}_{2} \mathrm{O}, 89.6 \mathrm{mg} \mathrm{I}^{-1} \mathrm{CaSO}_{4} \cdot 2 \mathrm{H}_{2} \mathrm{O}, 84.1 \mathrm{mg} \mathrm{I}^{-1} \mathrm{NaHCO}_{3} \cdot 3 \mathrm{H}_{2} \mathrm{O}\right)$ in plastic bottles. Three of the particles were exposed to the standard US EPA protocol, whereas the remaining three were exposed to simulated gastric fluid (Table 1).

Percent lead dissolution was calculated at selected time intervals, using Equation 1. Total lead was quantified after completion of the experiment, by employing full heated digestion of the samples at $85-90{ }^{\circ} \mathrm{C}$. The full digestion revealed that total lead (denominator of Equation 1) in each triplicate sample set (EPA and SGF) was $1777 \pm 363 \mu \mathrm{g} \mathrm{I}^{-1}$.

$\mathrm{Pb}$ Dissolution (\%) $=\frac{\text { Measured Lead Concentration in Sample }}{\text { Total Lead Concentration in Sample }} \cdot 100$

Actual particles collected from the apartment complex of a lead-poisoned child in Durham, North Carolina were used in a parallel experiment. The dissolution behavior of six leaded particles, with weight of $5.0 \pm 0.5 \mathrm{mg}$, was examined in EPA versus SGF solutions. The full digestion undertaken in the end of the experiment revealed that total lead (denominator of equation 1) in each triplicate sample set was $2132 \pm 353 \mu \mathrm{g} \mathrm{I}^{-1}$ for the Durham solids. All samples were analyzed for lead using ICP-MS. 


\subsection{Review of the Washington DC lead-in-water crisis}

Following the experimental part of this work, a brief and critical review of the Washington DC lead-in-water crisis from 2001-2008 is presented. Recently acquired lead-in-water data from selected DC schools are also presented.

\section{RESULTS AND DISCUSSION}

\subsection{Lead dissolution under the standard US quantification protocol versus SGF}

After the minimum sample holding time of 16 hours, the Greenville particles dissolved at a level of $27 \%$ under the standard preservation protocol (Figure 2). Dissolution in the simulated gastric fluid reached $47 \%$ (Figure 2). In other words, if water containing these particles had been collected at the tap, the measured lead concentration would have been $27 \%$ of the actual. At the same time, if that water had been consumed, a significant portion of the particulate lead would become likely bioavailable, since lead dissolution inside the human stomach would reach $47 \%$. This is probably due to the presence of chloride, warmer temperature and lower $\mathrm{pH}$ inside the human stomach, relative to the EPA protocol (Table 1). After 48 hours of exposure to the SGF and the EPA preservative, lead dissolution reached $66 \%$ and $40 \%$ respectively (Figure 2 ). These results illustrate high potential bioavailability of the lead solids collected from the faucet aerator, and incomplete dissolution under the standard sample preservation protocol.

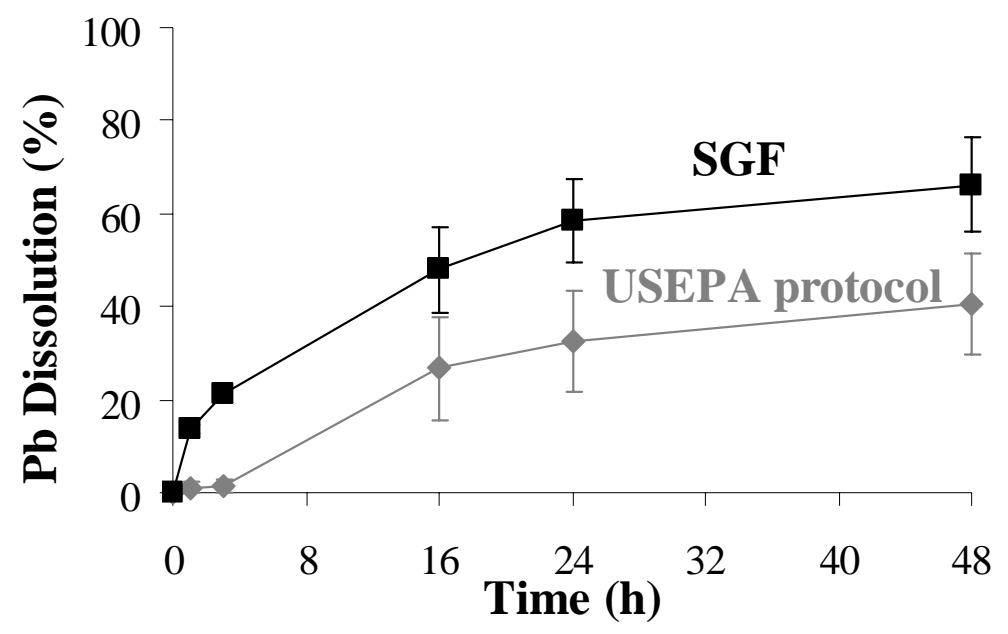

Figure 2. Lead dissolution versus sample holding time, for leaded particles collected from a home faucet in Greenville, North Carolina. The error bars represent $90 \%$ confidence intervals over triplicate samples. (Reprinted from Journal AWWA, Vol. 99, No. 6, by permission)

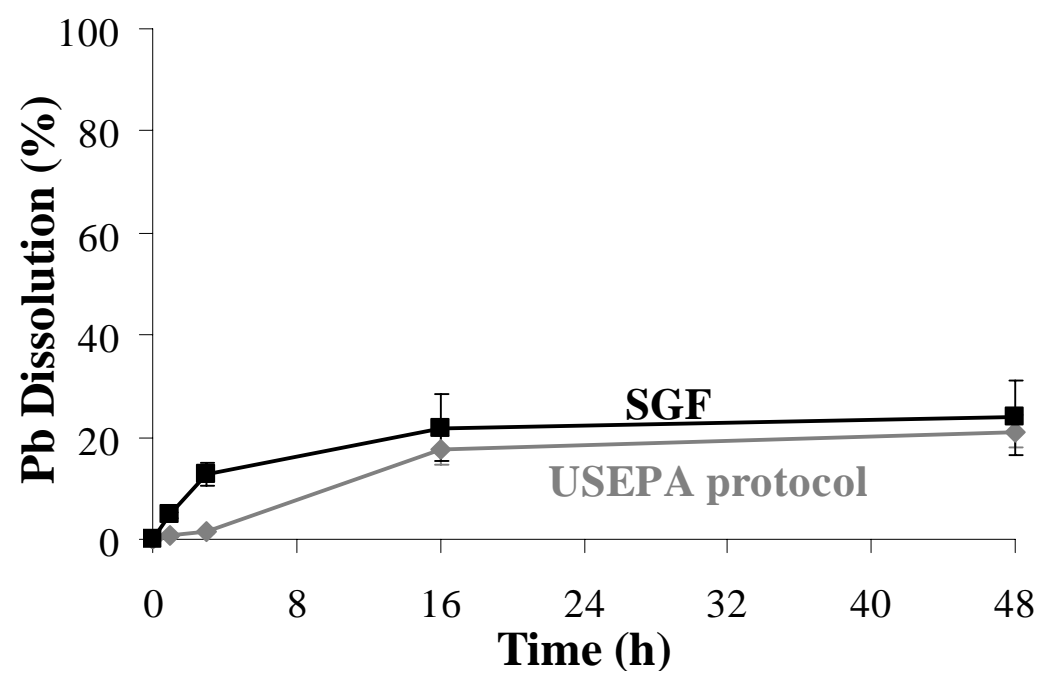

Figure 3. Lead dissolution versus sample holding time for leaded particles collected from a home faucet in Durham, North Carolina. The error bars represent $90 \%$ confidence intervals over triplicate samples. (Reprinted from Journal AWWA, Vol. 99, No. 6, by permission) 
In the case of the Durham solids, after the minimum sample holding time of 16 hours, particles in SGF released 22\% of their lead content, while particles in the EPA preservation released $18 \%$ of the lead (Figure 3 ). This difference was not statistically significant (Error bars on triplicate samples plotted, Figure 3). By the end of 48 hours, lead dissolution was $24 \%$ and $21 \%$ in SGF and EPA respectively, but this difference was not statistically significant at the $90 \%$ confidence level either. As with the particles collected in Greenville, a final full heated digestion confirmed that the Durham solids detached from leaded solder, based on the release of tin along with the lead, and absence of copper and zinc (results not presented herein). This is consistent with identification of lead solder joints in the plumbing during the site investigation, as well as with the results of SEM analysis.

\subsection{Case Study: Lead in Washington DC Drinking Water, 2001-2008}

\subsubsection{Background}

In November 2000, Washington DC switched its disinfection treatment from free chlorine to chloramine in order to comply with national regulations for the reduction of disinfection byproducts in US drinking water. Approximately two years later, the local drinking water utility (Washington DC Water and Sewer Authority-WASA) reported to the EPA, which regulates and oversees Washington DC's drinking water, that about half of the DC homes it tested in 2001-2002 had levels of lead exceeding EPA's action level of $15 \mathrm{ug} \mathrm{I}^{-1}$. The EPA initially characterized these findings as a "serious public health issue" and ordered the gradual replacement of residential lead pipes in the system (Leonnig and Nakamura, 2004). At the same time, however, Washington DC residents in homes with contaminated drinking water were not informed about the extent of the contamination, and the public at large was not clearly instructed on simple steps to minimize potential exposure to elevated levels of lead in water. Follow up testing in 2003 revealed that in some homes lead levels were in the hundreds and even thousands of $\mathrm{ug}^{-1}$ (Reel and Cohen, 2004). These news did not reach the public until January 2004, when a front page article in the Washington Post (Nakamura, 2004) alerted City residents to the severity of the contamination.

Following media coverage, the drinking water utility and related agencies initiated a response to the elevated lead. After being advised that standard guidance regarding 1-minute flushing of lead from the lines was inadequate (Edwards, 2004), the authorities eventually recommended that plumbing lines be flushed 10 minutes continuously and that the water collected afterwards be filtered for lead before cooking or drinking. This action was recommended only for homes known to have lead pipe. The agencies also began to add a corrosion inhibitor to the water in an attempt to reduce lead contamination. Finally, an accelerated program was undertaken to replace lead service lines, an effort which was recently scaled down (DC WASA, 2008). In January 2006, the drinking water utility announced that its corrosion control intervention had worked, since samples collected for compliance with EPA regulations had been under the lead action level for an entire calendar year (DC WASA, 2006). Ever since, DC residents have been assured that the public health crisis is over and their tap water is safe to drink. It is now also widely acknowledged that the switch from chlorine to chloramine was the main event that triggered high lead in DC water from 2001-2004, as had originally been suggested by Edwards and Dudi (2004). Mechanistic insights that explain the lead spikes after such a disinfectant switch have also been published (Switzer et al., 2006).

\subsubsection{The Official Interpretation of the 2001-2004 DC Lead Crisis}

The events of 2001-2004 have been subject to numerous investigatory hearings, retrospectives and reports. The official narrative on health effects and water safety suggests that: a) the excessive lead-in-water levels of 2001-2004 had no identifiable health impact on DC residents (CDC, 2004;Guidotti et al., 2007); and b) the drinking water utility's compliance with EPA regulations is tantamount to proof that the city's drinking water is safe (US EPA, 2007). These conclusions have further reinforced the notion that, when compared to deteriorated lead paint, dust, and soil, Washington DC's drinking water poses an insignificant health concern. Until recently, for example, the DC Department of Health routinely failed to sample the water consumed by children with lead poisoning. Additionally, in 2007 the DC Department of the Environment drafted childhood lead poisoning prevention legislation that 
addressed lead paint, dust, and soil, while excluding lead in water (DC Department of the Environment, 2007).

\subsubsection{Revealing Potential Weaknesses in the Official Story}

Contrary to statements about the lack of harm associated with DC's lead-in-water crisis, investigatory research by the third author of this paper revealed that during 2001-2004 drinking water was the sole source of lead identified for several lead poisoned children. The basis for this conclusion, which has not been contradicted or refuted, is the original reports made to the DC Department of Health and interviews with parents of lead poisoned children. In addition, some children with lead poisoning did not have identified lead paint or dust hazards in their homes. These and other findings indicate that lead in water had a greater public health impact in DC than generally acknowledged, as is discussed in more detail elsewhere (Edwards et al., 2009). Even in 2007-2008 (over 2 years after Washington DC's water was declared below the EPA action level), 9 of 97 childhood lead poisoning cases for which water was assessed (in 35\% of cases no water samples were taken) revealed elevated lead levels at the tap (DC Department of the Environment, 2008). In three of these cases no other source of lead was identified (DC Department of the Environment, 2008). Because the assessments did not follow the standard EPA sampling protocol, they may have, in fact, missed elevated levels of lead in water in many of the homes.

Print media coverage during 2004-2005, independent scientific research, whistleblower reports from a former DC water treatment chemist, and an EPA 2006 citation of WASA for data management violations suggest that the water utility sampled water in a way that can make lead appear lower than it actually is. Independent sampling by Virginia Tech and the University of California, Berkeley demonstrated that DC's lead-in-water problems persisted at least through the summer of 2005 (Adarkwah et al., 2005). In addition, 2006-2007 testing at DC public schools revealed widespread contamination, despite the use of a sampling protocol that reduces detected lead by flushing the plumbing a minimum of 50 minutes the night before sampling.

In 2008, citizens' groups discovered and alerted EPA Headquarters to the fact that the water utility pre-flushed routinely, even when collecting samples for compliance with EPA regulations. EPA responded that such a sampling protocol "goes against the intent of the [LCR] monitoring protocol" (Dougherty, 2008). Despite the modified protocol, seventy-seven percent of schools had at least one tap with lead levels above the EPA action level for home taps. Moreover, ten percent of schools produced water samples with over $700 \mathrm{ppb}$ lead - a disturbing fact given that an equivalent amount of lead detected in toys would trigger recalls because of concern over acute health effects in children who might possibly ingest the contaminated items (US CPSC, 2005). Our own independent testing at six DC schools in early 2008 revealed that, even though lead levels showed a significant decrease due to the remedial measures implemented, lead problems still persist at $2-41 \%$ of school taps sampled (Table 3). The highest lead detected was $1987 \mathrm{ug} \mathrm{I}^{-1}$, significantly higher than the EPA recommended guideline for schools of $20 \mathrm{ug} \mathrm{I}^{-1}$ (US EPA, 1994b), as well as the EPA action level of $15 \mathrm{ug} \mathrm{I}^{-1}$ for home taps (Table 3).

Table 3. Water lead monitoring data from selected Washighton DC Public Schools in 2008

\begin{tabular}{|c|c|c|}
\hline School & Taps with Lead > $15 \mathrm{ug} \mathrm{I}^{-1} *(\%)$ & Highest Lead Detected $\left(\mathrm{ug} \mathrm{I}^{-1}\right)$ \\
\hline $\mathrm{A}$ & 14 & 521 \\
\hline B & 41 & 1987 \\
\hline $\mathrm{C}$ & 11 & 65 \\
\hline $\mathrm{D}$ & 2 & 44 \\
\hline $\mathrm{E}$ & 14 & 62 \\
\hline$F$ & 21 & 413 \\
\hline
\end{tabular}

*Even though EPA guidance for school drinking water recommends that drinking water samples for lead do not exceed $20 \mathrm{ug} \mathrm{I}^{-1}$, DC Public Schools have used the action level of 15 $\mathrm{ug} \mathrm{I}^{-1}$, which refers to home taps, as the "failure criterion". For consistency with their approach, failure rates in the table correspond to the $15 \mathrm{ug} \mathrm{I}^{-1}$ threshold. 


\section{CONCLUSIONS}

The experimental part of this work established that:

- When present in tap water, lead particles might pose a significant public health threat. This is because the presence of chloride, warm temperature, low $\mathrm{pH}$ and mild agitation inside the human stomach may render a significant fraction of particulate lead bioavailable once ingested. Under the experimental conditions, up to $66 \%$ of the particulate lead dissolved in simulated gastric fluid after 48 hours.

- Standard sampling protocols in the US are not adequate in quantifying the true extent of that exposure. Even though the solder particles collected from two different systems did not behave similarly in laboratory experiments, a substantial fraction of the particulate lead was likely bioavailable in both cases. At the same time, the standard preservation protocol was inadequate in measuring all the lead, and in fact "missed" up to $80 \%$ of the lead present in water.

Investigation of the Washington, DC case study:

- Confirmed that lead in drinking water may pose a health hazard, even though it is often neglected compared to lead paint, soil and dust.

- Illustrated how lead-in-water problems can be underestimated by sampling protocols that circumvent the intent of US regulation. Addition of steps such as "pre-flushing" the lines the night before sampling can produce results lower than they are during normal water use.

- Prompted independent testing at selected DC school taps by the authors. Based on 2008 sampling results, some lead-in-water problems still persist at DC schools, even after remedial measures were implemented.

\section{ACKLOWLEGEMENTS}

The experimental part of this work was supported by the National Science Foundation (NSF) under grant DMI- 0329474. Opinions and findings expressed herein are those of the authors and do not necessarily reflect the views of the NSF. The authors would also like to thank Dr. Paolo Scardina for conducting the SEM analysis. Finally, the participation of high school volunteers in the DC school sampling events is greatly appreciated.

\section{REFERENCES}

Adarkwah N.E., Ararso I., Garcia N., Goldman A., Lieu C., Mondragon J., Swamy V., Unigarro M., Cuff K. (2005), Investigation of Higher than Standard Lead Concentrations in Drinking Water from Washington, DC. American Geophysical Union Meeting. http://adsabs.harvard.edu/abs/2005AGUFMED43A0839A (accessed 28/12/2007).

Bellinger D.C. and Needleman H.L. (2003) Intellectual impairment and blood lead levels, N Engl J Med., 349, 500-502.

CDC-Centers for Disease Control and Prevention (2004), Blood Lead Levels in Residents of Homes with Elevated Lead in Tap Water - District of Columbia 2004, Morbidity and Mortality Weekly Report, 53, 268-270.

DC Department of the Environment (2008). Draft Lead Task Force Update.

DC Department of the Environment (2007), Comprehensive Lead-Based Paint Risk Reduction Act.

DC WASA-Water and Sewer Authority (2008). News release: DC WASA Board Revises Lead Service Line Removal Program.

DC WASA-Water and Sewer Authority (2006), News release: District drinking water meets federal requirements for Lead Levels.

http://www.dcwasa.com/site archive/news/press release250.cfm (Accessed 5/1/2008)

Dougherty, C. Director, Office of Ground Water and Drinking Water, EPA (2008). Personal communication on $9 / 12$.

Edwards M. (2004). Testimony to the U.S. House of Representatives. http://www.dcwatch.com/wasa/040305h.htm (Accessed 5/1/2008).

Edwards M. and Dudi A. (2004), Role of chlorine and chloramine in corrosion of lead- bearing plumbing materials. Journal American Water Works Association, 96, 69-81. 
Edwards M., Triantafyllidou S. and Best D. (2009), Elevated Blood Lead in Young Children Due to Lead-Contaminated Drinking Water: Washington, DC, 2001-2004. Environmental Science and Technology, 43, 1618-1623.

Guidotti T.L., Calhoun T., John O., Davies-Cole J.O., Knuckles M.E., Stokes L., Glymph C., Lum G., Moses M.S., Goldsmith D.F., Ragain L. (2007), Elevated Lead in Drinking Water in Washington DC, 2003-2004: The Public Health Response. Environmental Health Perspectives, 115, 695-701.

Intawongse M., Dean R.J. (2006), In vitro testing for assessing oral bioaccessibility of trace metals from soil and food samples, Trends Anal. Chem, 25, 876-886.

Leonnig C.D., Nakamura D. (2004). DC Knew of Lead Problems in 2002. Washington Post, 29 March:A01.

Nakamura D. (2004), Water in DC Exceeds EPA Lead Limit. Washington Post, 31 January:A01.

Reel M. and Cohen S., (2004). Little Action on Lead Warnings. Washington Post, 14 March:A01.

Switzer J.A., Rajasekharan V.V., Boonsalee S., Kulp E.A., Bohannan E.W. (2006), Evidence that monochloramine disinfectant could lead to elevated $\mathrm{Pb}$ levels in drinking water. Environmental Science and Technology, 40, 3384-3387.

Triantafyllidou S., Parks J. and Edwards M. (2007), Lead Particles in Potable Water. Journal American Water Works Association, 99, 107-117.

Triantafyllidou S. (2006), Addressing and Assessing Lead Threats in Drinking Water: Non-Leaded Brass, Product Testing, Particulate Lead Occurrence and Effects of the Chloride to Sulfate Mass Ratio on Corrosion. Master's Thesis, Department of Civil and Environmental Engineering, Virginia Tech.

US CPSC-Consumer Product Safety Commission, Office of Information and Public Affairs. (2005), CPSC Announces New Policy Addressing Lead in Children's Metal Jewelry. Accessed 7/7/08 at http://www.cpsc.gov/cpscpub/prerel/prhtml05/05097.html

US EPA-Environmental Protection Agency (1991). Safe Drinking Water Act Lead and Copper Rule (LCR). Federal Register, 1991;56:26460-26564.

US EPA (2005), Lead and Copper Rule: A Quick Reference Guide for Schools and Child Care Facilities that are Regulated under the Safe Drinking Water Act (EPA 816-F-05-030).

US EPA (1994a), Method 200.8: Determination of Trace Elements in Waters and Wastes by ICPMS. Revision 5.4. Environmental Monitoring Systems laboratory, Office of Research and Development, US EPA, Cincinnati, Ohio 45268.

US EPA. (1994b), Lead in Drinking Water in Schools and Non-Residential Buildings. EPA 812-B94-002. Accessed 6/8/08 at www.epa.gov/safewater/consumer/leadinschools.html.

US EPA (2007), Lead in DC Drinking Water. http://www.epa.gov/dclead/ (accessed 28/12/2007).

US Pharmacopoeial Convention (2005), United States Pharmacopoeia 29-National Formulary 24, p. 3171. Rockville, MD. 